\section{Questión}

Periodismo / Comunicación ISSN 1669-6581
- Av. $44 \mathrm{~N}^{\circ} 676,1^{\circ}$ piso

CP 1900 - La Plata - Argentina

www.perio.unlp.edu.ar/question

\title{
La cola y el dato: Narrativas sociales e interacción en redes digitales en la Cuba que enfrenta a la COVID19
}

\section{The Queue and the Fact: Social Narratives and Interaction in Digital Networks in Cuba Facing COVID19}

Fidel A. Rodríguez / fidelalejandrof@gmail.com Profesor de Comunicación Hipermedia, Tecnología y Sociedad en la carrera Periodismo de la Facultad de Comunicación de la Universidad de La Habana. Investiga temas de cultura digital, redes y participación en ámbitos locales en Cuba. Coordina el proyecto Enredes, Información y Comunicación para la gestión participativa del desarrollo local.

8:05 am entra el primer mensaje al grupo: "Buenos días, ¿alguien puede decirme dónde puedo encontrar leche en polvo?" En algún momento del día alguien contestará, o no, pero no está de más preguntar.

El acceso a los alimentos parece ser la narrativa central para muchos ciudadanos cubanos en medio de la lucha contra la COVID19. Desde el inicio de los servicios de datos móviles en diciembre del 2018 , entre las más regulares formas de colaboración colectiva en redes que han aparecido se encuentran los grupos de WhatsApp y Telegram dedicados a alertar sobre la existencia de productos en carestía en las tiendas. Estos espacios parecen resumir, por acento o contraste, buena parte de los retos del país para enfrentar y sobrevivir a la crisis y a la vez sostener una agenda de gestión gubernamental de equidad y protección de las mayorías y los sectores de situación más precaria. 
En otras geografías, la información y las redes digitales se confirman por estos días como el producto más valioso de la época, distribuyendo la fascinación global en millones de pantallas sobre el performance funerario del atascamiento de los tanqueros de petróleo que no tienen donde descargar su carga de valor inferior a cero. En Cuba, como en otros lugares del mundo, garantizar la alimentación y acceso a los bienes primarios, para la nación y cada familia, es un escenario primordial. La vida tiene otras prioridades allende a la conexión virtual, pero estas prioridades a su vez se cogestionan y revalorizan en la información circulante en redes digitales.

Cuba tiene casos de COVID 19 desde mediados de marzo. Las medidas de contención dictaminadas por el Estadoi de manera preventiva, así como la existencia de un sistema de salud pública, gratuita e universal, con experiencia, recursos y estructuras para enfrentar riesgos epidemiológicos, han permitido un crecimiento gradual y controlado de la enfermedadii. El enfoque preventivo parece haber estado acompañado de un consenso social y amplias demandas ciudadanas para su implementación. El Estado ha desarrollado a su vez un grupo de medidas de protección social del empleo y los ingresosiii.

Sin embargo, la incertidumbre ante el escenario económico futuro, tomando en cuenta la fragilidad precedente del año anterior, ponen el foco de la preocupación social y el esfuerzo ciudadano en aprovisionarse para una temporada difícil.

Si bien se hace énfasis en el distanciamiento social como medida de prevención principal; "las colas", largas filas y aglomeraciones de personas esperando para acceder a un servicio, son un evento cotidiano que amenaza con expandir el virus y convierte el acceso a insumos básicos en una experiencia compleja y tediosa al calor del cercano verano.

"Las colas" son un espacio de interacción donde se ejecuta y se recrea la identidad nacional a la par de las opiniones y concepciones sobre la política y los modos individuales de enfrentar la vida, incluso a un metro y medio de distancia, si esto posible. "La cola" siempre trae a coalición y extrapola las conversaciones hacia "la cosa", aleph de la política y la cotidianidad. ¿Cómo resolver la cosa, o "cómo está la cosa?" puede ser preguntas sobre cómo agilizar la fila o sobre cómo acabar con los dilemas de la economía, casi siempre resueltos con algún chiste y burla colectiva. En la cola aparece también "la lucha", el modo del ciudadano común de enfrentar las crisis, término que a veces nombra alguna forma de corrupción. Estas colas son sobre todo espacio para anécdotas repetidas en otras plataformas y espacios. "Ayer en la cola escuché", 
suele ser un buen modo de iniciar una conversación, un punto de inicio de un debate en Facebook o un estado de Whatsapp.

Un video remix del dibujo animado más popular del país referido a las colas para alimentos lo relata: En una situación de guerra, los personajes se hacen pillerías entre sí y terminan frustrados 1.

La escasez de productos básicos se ha incrementado con el contexto del virus, pero tiene razones multicausales y precedentes que son factores importantes para la ansiedad social vinculada a ello, desde las compras de pánico hasta el desabastecimiento recurrente. El año anterior se caracterizó por rotativas ausencias de algunos productos muy demandados en determinados momentosiv.

El Estado cubano provee regularmente una cuota de alimentos básicos a todos los ciudadanos a través de un sistema de distribución normado que garantiza una dieta elemental y con refuerzos en los grupos más vulnerables a afecciones de salud, la cual se ha visto incrementada con algunos productos en este escenario. Dicho sistema de distribución normada, conocido como "La Libreta", parecía tener los días contados (su desaparición era motivo de múltiples bromas en televisión nacional) a partir de la opinión mayoritaria sobre su condición de fuente de inequidad y lastre económico (invierte en quien necesita y en quien no y no permite políticas de mayor incidencia). Su desaparición solo parecía demorada por la digitalización de sus registros poblacionales, lo cual posibilitaría la consecutividad de su carácter de protección social. Sin embargo, la experiencia y legado de escasez asociado a la pandemia parece volverlo a poner como la única herramienta de distribución consolidada a riesgos de quedar a expensas de un amplio y alzado mercado negro.

El regreso a una forma de distribución controlada parece ser la más aceptada variante en un país que no dispone de recursos para importar y presenta muchas dificultades para su sostenibilidad alimentariav. Para abril del 2020, el gobierno del país ya ha alertado sobre desarrollo de inversiones para incrementar y microlocalizar la producción y distribución agrícola como vía principal para garantizar el acceso a los alimentos.

En este complejísimo escenario económico, un país que invierte el 60 por ciento de su presupuesto en sus sectores de Salud y Educación, completamente gratuitos a todos los 
niveles, asume el reto de mantener su proyección social y política en el mundo pospandemia. La supervivencia al coronavirus, en "la cola" o en la tv, parece ser una conversación sobre cómo vivir en el mundo futuro.

Desde finales de marzo, se puede escuchar en las ciudades de Cuba, como en otros países del mundo, un aplauso a las $9 \mathrm{pm}$ al personal de la salud. La relevancia de este proceso es que parece ser el primer proceso de colaboración en redes digitales masivo organizado en el rango de unas horas en el país.

Con la apertura del servicio de datos móviles en diciembre del 2018, las redes digitales se han convertido en un espacio central para la articulación y movilización de agendas ciudadanas, nacionales y locales; para el debate político y cultural, así como de la percepción gubernamental y social de la opinión pública.

Para febrero del 2020, el 63 (7.1 millones de 11,3) por ciento de la población era usuario de Internet, de ellas 3.4 millones a través del servicio de datos móviles (Perdomo ,2020). Aun, cuando el costo del servicio por celulares es considerado alto para la mayoría de los usuarios (unos 11 dólares por $1 \mathrm{gb}$ ).

La exigencia por la rebaja del precio del servicio fue un tema central en los debates en red los primeros días de desarrollo medidas de aislamiento. Aunque la demanda social solo hace énfasis en el coste individual, la circunstancia pone a prueba el modelo de uso de las redes digitales existente en el país y los servicios disponibles.

Las plataformas de educación a distancia, compra y pagos en línea o gestión de trámites online han tenido que fortalecerse de manera apresurada, o se han visto sobre saturadas por un rol que no tenían hasta le momento. En el caso de la docencia, han debido convertirse en complementos de la educación televisada en la etapa preuniversitaria, bajo el principio de garantizar una educación para todos y libre de costo. Las plataformas existentes de gobierno electrónico no disponían hasta el momento, con carácter provincial o nacional en su mayoría, de espacios para demandas ciudadanas o gestión de documentos, por lo que buena parte de los trámites siguen asociados a la presencia física.

Aun y cuando se privilegian en las tarifas de acceso los espacios nacionales, como en buen aparte del mundo, la mayoría del tiempo de navegación ocurre en sitios de redes sociales digitales como Faceboook, WhatsApp y Telegram. En ellos se dirime buen aparte de la interacción social digital de algunos sectores. El peso de estas interacciones en la opinión 
pública y en la agenda política es creciente, en una sociedad con una amplia comunidad trasnacional de migrantes, aun cuando en el entorno nacional solo participe de manera recurrente la parte de la sociedad que puede pagar el servicio con esa regularidad. Algunos medios de comunicación digitales también son un lugar de profundo debate público.

Aun así, sería poco preciso identificar los usos de estos espacios como propios de solo un grupo social dado, teniendo en cuenta los amplios procesos de circulación de información asentados en una larga tradición de intercambios persona a persona. Por esas razones, los espacios como los grupos de WhatsApp para encontrar alimentos en microgeografías en la ciudad de la Habana son un entorno-recurso creciente para la gestión cotidiana de la vida.

Estas dinámicas de intercambio en redes están en Cuba ampliamente condicionadas por el diferendo con los Estados Unidos. El gobierno de ese país destina anualmente millones de dólares de fondos públicos a sostener grupos, intuiciones y medios con una agenda de transformación y subversión del sistema político y gubernamental cubano (NED, 2018), incluyendo una fuerza de trabajo especial del Departamento de Estado dedicada al Internet en Cuba. Esta circunstancia conlleva a una reacción defensiva que expone las interacciones en redes a un permanente riesgo de parcialización política y enfrentamiento, y donde en varias ocasiones formas de asociatividad y disensos son señaladas o presionadas legal e institucionalmente. Esto lleva a muchos sectores a dar un paso lejos de su participación en estos espacios y solo concentrarse en sus dinámicas cotidianas.

Aun así, la revisión de las políticas, medidas y decisiones puntuales y calidad de servicios son una agenda cotidiana en algunas redes digitales, con el acceso a los alimentos como narrativa central.

En junio del año anterior, ocurrió un profundo debate sobre la legalización de redes comunitarias desarrolladas con sistemas e infraestructuras propias por comunidades de videojugadores en varios lugares del país. Estas redes terminaron circunscritas técnica y legalmente a un carácter privado o a un enlace con centros locales de computación para su función de juegos. De haber sido potenciadas como espacios de cooperación y servicio comunitario, hubieran ofrecido una importante alternativa para la gestión de soluciones locales en tiempos de distanciamiento social y dificultad para la distribución de mercancías, así como la organización de la atención a los sectores vulnerables. 
La emergencia de articulaciones feministas, animalistas, religiosas o juveniles que se pudieron visibilizar en redes en el último año, tendrán que apelar a múltiples recursos para sostener sus agendas en medio del énfasis colectivo en el enfrentamiento a las crisis asociadas a la enfermedad. Algunos de estos grupos sociales, y no siempre los promotores de fórmulas más propositivas del entendimiento y la convivencia social parten con ventajas por su experiencia y su infraestructura organizativa reticular.

El país no ha podido desarrollar plenamente un programa de alfabetización comunicativa digital que permita ofrecer herramientas a los ciudadanos en este contexto, si bien cuenta con múltiples fortalezas y experiencias que pueden contribuir a ese propósito.

La continuidad del compromiso de servicio público de las telecomunicaciones, el desarrollo de sus infraestructuras y funcionalidades en un esquema de sostenibilidad y expansión no basado exclusivamente en el cobro por el acceso, el fortalecimiento d la innovación social y la cultura de cooperación y consenso; aparecen como discusiones útiles para que el sentido y aspiración equitativa y participativa del proyecto social y político cubano puedan sobrevivirle a una etapa de fuerte escasez e individualismo de supervivencia.

Esta visión de sostenibilidad socialista, de equidad próspera a largo plazo, resulta explícita en el discurso político de la dirección del país. Sin embargo, los retos para alcanzarla parecen no ser pocos ni desconectados entres sí; mientras los esfuerzos, soluciones y conversaciones, sí. El bienestar común y el modo de alcanzarlo, necesitaría de espacios y entornos para cogestionarse y definirse en interacciones y narrativas sociales.

Tras una mañana en una fila de cientos de personas para adquirir alimentos en el municipio más densamente poblado de La Habana, una amiga decide hacer una larga publicación en Facebook quejándose de la peligrosa e insostenible situación. No etiqueta al gobierno local, o a alguna instancia responsable. No hace sugerencias. Está solo cansada y preocupada. Tampoco es habitual que le respondan en este espacio, que es su lugar de socialización natural. Es una conversación con ella misma y los amigos que compartimos su reto. Horas antes había posteado una foto con un ticket con el número 256 y una sonrisa divisable bajo su nasobuco. La red puede o no servirle de solución a la situación de acceso a los alimentos, pero aparece como un lugar donde explicita su incertidumbre y la conecta con la de otros. El valor de la información que comparte no es sopesable con el volumen de su compra de comida, pero ambos pesos van definiendo la ruta hacia dónde vamos todos. 


\section{Bibliografía}

- Portal, José Ángel. ACN. Sistema de salud cubano asegura la atención a los pacientes ante la COVID-19. 3.4.2020. http://www.acn.cu/salud/62905-sistema-de-salud-cubanoasegura-la-atencion-a-los-pacientes-ante-la-covid-19

- BBC Mundo: Coronavirus: qué capacidad tienen realmente los países de América Latina para hacer frente a la epidemia de covid-19, 30.3.2020. https://www.bbc.com/mundo/noticias-america-latina-51916767

- National Endownment for Democracy (NED): Advocating for a Human Rights Framework for Cuba (2018). https://www.ned.org/region/latin-america-andcaribbean/cuba-2018/

- Perdomo, Jorge Luis. Entrevista Mesa Redonda. 22.2.20

- Informe Nacional sobre Agenda 2030, Cuba. Informe Voluntario de Cuba, 2019. http://foroalc2030.cepal.org

Notas

\footnotetext{
i Paralización de las actividades sociales que impliquen concentración de personas y de actividades comerciales no relacionadas con la alimentación y aseo, restricción gradual de la trasportación urbana y por carretera; cierre de fronteras excepto situaciones excepcionales y llegada de mercancías y progresiva restricción de movilidad en determinadas zonas de eventos de contagio de fuente indeterminada; así como paralización de clases.

ii Se realizan pruebas masivas gratuitas de test rápidos a todos los afectados con enfermedades respiratorias y pruebas PCR a quienes resultan positivos. Los contactos de casos confirmados son aislados en centros con alimentación y atención médica. Se realizan pesquisas médicas casa por casa y autopesquisa a través de Internet.

Según un reporte de la BBC, Cuba partió al enfrentamiento a la pandemia con el mayor gasto per cápita de salud de Latinoamérica y el mayor porciento de camas por habitantes, solo superado por Barbados e Islas Vírgenes (BBC, 2020). Fuentes oficiales cubanas señalaban la existencia de 122 habitantes por médico en 2018 (MINSAP). A inicios de abril se señalaba la disponibilidad de unas 5 mil 104 camas y 651 camas de cuidados intensivos, planeando llegar a unas 700 para unas 6,36 por 100 mil habitantes, una de las más altas del continente Portal, 2020). Para finales del mes de abril se había alcanzado un pico de 2076 test rápidos diarios y más de 35 mil en total. Si bien el cuadro de medicamentos básicos, distribuidos a precios módicos se ha visto severamente afectado en los últimos años en el país; Cuba produce y exporta algunos de los medicamentos esenciales en la atención a la enfermedad en muchos países, como el Interferón Alfa B, incluido de manera gratuita a todos los pacientes.

iii Otro paquete de medidas garantizó la conservación de las plazas laborales y la disponibilidad de salario durante el primer mes en casa a todos los trabajadores del sector estatal, el mayor empleador del país, cuyas labores fueran suspendidas. También se aplicaron la excepción de impuestos a los trabajadores privados y la moratoria en el pago de servicio de utilidades entre otras.
} 


\begin{abstract}
iv Estas circunstancias están asociadas a las restricciones y sanciones comerciales y financieras impuestas a Cuba y a empresas de terceros países por la legislación norteamericana, desde hace 60 años, para el uso del dólar y la compra de productos a compañías con vínculos comerciales con Estados Unidos. Es decir, con buena parte del mercado global. Su ejecución ha sido particularmente incisiva en la administración Trump. También dependen de las deficiencias estructurales en los modos de gestión y planificación nacionales, así como a la escasa disponibilidad de divisas para la importación de insumos. El incremento turístico entre los años 2014 y 2017 propiciaron el surgimiento múltiples negocios privados cuya demanda se recargó sobre los productos destinados a al consumo social, lo cual provocó una tendencia alcista de los precios que se mantiene hasta hoy.

v Convertido progresivamente en una economía de servicios, el país vinculaba sus ingresos en los últimos treinta años al turismo, la atención médica profesional en países extranjeros y la exportación de níquel entre otros. Con los cambios políticos en la región se cerró la fuente de ingresos por servicios médicos y la pandemia global ralentizará a largo plazo el turismo y la llegada de remesas del exterior. En el año 2008, las máximas figuras políticas insistían en la necesidad de transformar la producción agrícola de país, que importaba buena parte de sus alimentos y mantenía la gran mayoría de sus tierras cultivables ociosas. Para enfrentar dicha situación se comenzó una reforma que propiciaba la entrega de terrenos a campesinos y transformaciones en los modos gestión de la economía agrícola. Un informe de Naciones Unidas en el 2018 confirmaba a partir de fuentes nacionales que la situación estaba lejos de resolverse. A esto se le suma una progresiva e intensa sequía y otros eventos climatológicos y tectónicos extremos que contribuyeron a la despoblación de zonas rurales. En esto incide colateralmente que Cuba es un país con un alto indicie de escolaridad e ingreso a la educación superior y un flujo de divisas importante desde otros sectores.
\end{abstract}

